\title{
The Lexical Knowledge and Avoidance of Phrasal Verbs: The Case of Egyptian Learners of English
}

\author{
Dina Abdel Salam El-Dakhs \\ College of Humanities, Prince Sultan University \\ PO box 66833 Rafha Street, Riyadh 11586, Saudi Arabia \\ E-mail: dinadakhs@yahoo.com
}

Received: 13-06-2015

Published: 01-01-2016
Accepted: 22-09-2015

doi:10.7575/aiac.ijalel.v.5n.1p.132
Advance Access Published: October 2015

URL: http://dx.doi.org/10.7575/aiac.ijalel.v.5n.1p.132

\begin{abstract}
Recent studies in different parts of the world have highlighted that phrasal verbs constitute a learning difficulty for English language learners despite their confirmed significance and high productivity in English. Proposed explanations include cross-linguistic differences, the complex nature of phrasal verbs, low language proficiency and psychological factors. The present study examines this difficulty among an Arabic-speaking population of Egyptian undergraduates in a foreign language context. To this end, a total of 407 Egyptian undergraduates in a private English-medium university completed a paraphrase task, two gap-filling tasks and a survey. The results confirm the difficulty highlighted in earlier studies, particularly at the production level. The results also show that the under-representation of phrasal verbs in the participants' production can be interpreted in terms of cross-linguistic differences, passive learning for comprehension and limited language exposure. The study thus supports a multi-faceted model for the explanation of the limited use of phrasal verbs by English language learners, and calls for a revision of the English language teaching programs in Egypt.
\end{abstract}

Keywords: phrasal verbs, lexical knowledge, avoidance, vocabulary studies, contrastive linguistics

\section{Introduction}

Vocabulary studies have recently witnessed an increasing interest in the area of phraseology and multiple-word units (e.g., phrasal verbs, collocations and idioms). This interest emerged as a result of recurrent evidence that different types of word combinations, also known as lexical phrases, chunks and prefabs among others, occupy a large part of the native speaker's discourse. For instance, Erman and Warren (2000) estimate the percentage of prefabs in English spoken discourse at 58.6\% and in English written discourse at 52.3\%. This is in line with Willis's (2003) observation that "much of the language we produce is made up not of individual words, but of strings of words which we carry around with us as fixed phrases," (p.43). It has also become evident that principles of chunking and memorization of lexical units influence our mental lexicons during language acquisition. Besides, mastery of chunks or prefabs enhances communicative competence as the retrieval of ready-made elements during language processing saves planning time and facilities/ speeds up language comprehension and production.

The present study deals with phrasal verbs, an important aspect of English phraseology. Also referred to as "compound verbs," "poly-word verbs," "separable verbs," and "merged verbs," it has been difficult to reach a unified definition of phrasal verbs. For the purpose of the current research, phrasal verbs refer to "a structure that consists of a verb proper and a morphologically invariable particle that function as a single unit lexically and syntactically," (Liao \& Fukuya, 2004, p. 73). Phrasal verbs are of prime importance to English language learners as they are highly represented in the English language and are known as a peculiar characteristic of Germanic languages. Recent corpus analysis studies have also enhanced this significance when they ruled out the misconception that phrasal verbs are a sole feature of English conversation or informal discourse. Biber et al (1999), for instance, found the highest percentage of phrasal verbs in conversations and fiction, followed by news journalism and then academic writing. The latter genre, however, included almost half the number of phrasal verbs in conversations and fiction, which entails the appropriate use of phrasal verbs in formal occasions.

Despite their prime importance and high productivity in English, phrasal verbs have been a common source of difficulty for English language learners around the world. A survey of relevant studies is included in the literature review section, but for now reference can be made to difficulty in Iran (e.g., Barekat \& Baniasady, 2014), Oman (e.g., Abdul Rahman and Abid, 2014), Malaysia (e.g., Kamarudin, 2013; Zarifi \& Mukundan, 2014), Thailand (e.g., Saiya, 2011), China (e.g., Liao and Fukuya, 2004), Korea (e.g., You, 1999), Israel (e.g., Dagut and Laufer, 1985), among others. Various causes have been proposed to explain this difficulty including the peculiarity of phrasal verbs to a certain language family, the idiomaticity of some phrasal verbs, the special status and movement of the particles and the polysemous nature of a great deal of these verbs. 


\section{Statement of Research Problem}

The present study reflects an awareness of the importance of phrasal verbs and the difficulty English language learners face in their acquisition. The study aims to investigate the use of phrasal verbs among Egyptian undergraduates who study English in a foreign language context in order to assess their knowledge of this significant linguistic pattern, investigate if they tend to avoid using the pattern in their production and study the learners' perceptions for the minimal use of phrasal verbs in their speaking/ writing. This study is the first study to examine the Egyptian learners' use of phrasal verbs to the best of the author's knowledge. Few earlier studies have, however, investigated the use of phrasal verbs among other Arabic-speaking learners (e.g., Omani learners in Abdul Rahman and Abid, 2014). The present study will thus shed the light on the use of phrasal verbs among a new population.

It is worth noting that the motivation to conduct the study is double-fold. First, the researcher has herself noted the relatively poor command of Egyptian learners of phrasal verbs in her long years of teaching English in Egypt. This observation has triggered interest to examine the phenomenon empirically with the aim of providing a realistic assessment of the situation, contribute to raising awareness of the problem and probably present pertinent solutions. Second, investigating the literature, it has been noted that studies on the difficulty of learning phrasal verbs have been on the rise in different parts of the world. Various explanations have also been proposed to account for the learning difficulty including first language- second language (L1-L2) structural differences, the semantic complexity of phrasal verbs, the learning environment, etc. The researcher thus aims to contribute to research on this phenomenon, whether with reference to the learners' knowledge of phrasal verbs, their employment of the avoidance strategy and potential causes for the poor use of phrasal verbs in English learners' production. The study also examines the influence of increased language exposure on the use of phrasal verbs.

\section{Significance of the Study}

The significance of the present study stems from the contributions the results will make on theoretical and practical grounds. Theoretically, the study will help understand the learning of phrasal verbs by foreign language learners. This includes the nature of their receptive/productive knowledge in addition to their employment of the avoidance strategy. The study will also explore the effect of increased language exposure on the use of phrasal verbs and examine the learners' perceptions regarding the under-representation of phrasal verbs in the production of foreign language learners. These findings will further validate earlier studies and contribute to the discussion regarding the nature of the so-called avoidance phenomenon. On practical grounds, the findings of the present study will prove useful for varied languageeducation stakeholders particularly in the Egyptian context, including language instructors, course designers and textbook writers. It must be beneficial to learn about the learners' ability to understand and use phrasal verbs in order to enhance the language learning programs.

\section{Theoretical Background}

Examining the literature, different classifications of phrasal verbs can be found. For example, Dagut and Laufer (1985) classified phrasal verbs into three categories; (1) literal phrasal verbs (e.g., go out) whose meaning can be directly induced from their components, (2) figurative phrasal verbs (e.g., turn up) which have undergone a metaphorical shift of meaning and (3) completive phrasal verbs (e.g., burn down) in which the particle is linked to the result of the action involved. In the same vein, Laufer and Eliasson (1993) presented three types of phrasal verbs; (1) semantically transparent (that is, the meaning of the phrasal verb can be deduced from its components), (2) semitransparent (i.e., the meaning of the phrasal verbs may not be clear in isolation, but is disambiguated in context) and (3) semantically opaque (whose meaning cannot be induced from its components and must be processed as an idiom). It was found that semantically opaque or idiomatic phrasal verbs are generally the most difficult for language learners, and hence, are the most recurrent type for avoidance (e.g., Kamarudin, 2013; Sara \& Mohammadreza, 2013; You, 1999). The present study, thus, focuses on the use of non-literal (=idiomatic) phrasal verbs, which constitute major difficulty for English language learners.

In vocabulary studies, it is important to consider two aspects of lexical knowledge; i.e., receptive and productive. While the receptive knowledge entails the user's understanding of the given item during reading or listening, the productive knowledge refers to the user's ability to produce the given item in speaking or writing. Hence, the user's receptive knowledge of lexical items does not guarantee his/her ability to use them in language production. A language learner may understand vocabulary items, but fail to use them in speaking or writing. It is well-known in vocabulary studies that a language learner's receptive knowledge is much larger than his/her productive knowledge, and that both aspects of knowledge are important for the proper assessment of the overall vocabulary knowledge (Schmitt, 2010). In the present study, the learners' knowledge of phrasal verbs is assessed both receptively and productively for two reasons. The first reason is to provide a comprehensive picture of the Egyptian learners' knowledge of phrasal verbs. The second reason is to compare the learners' performance on the productive task with their performance on the avoidance task. This will help give a more accurate assessment of the avoidance phenomenon. A learner who solely possesses receptive knowledge of phrasal verbs cannot be really described as avoiding their use. A distinction needs to be made between those who possess the productive knowledge but still avoid using the verbs and those whose knowledge of the verbs is only receptive.

Another important concept that requires careful examination is 'avoidance'. The phenomenon of avoidance in second language learning is observed "when specific language structures are under-represented in the learner's production (written or spoken) in comparison with native-speaker production" (Ellis, 1986, p. 293). Schachter (1974) first 
highlighted this phenomenon in her study of the use of relative clauses by Chinese, Japanese, Persian and Arab learners of English. She pointed out that the predictions of Contrastive Analysis that Chinese and Japanese learners face more difficulty using relative clauses due to the lack of the target structure in their native languages were confirmed. The confirmation was, however, reflected in the small number of relative clauses in the Chinese and Japanese learners' production, not in the number of erroneous clauses. This discovery drew attention to the importance of carefully observing the learners' avoidance behavior in addition to analyzing their errors in order to provide a more comprehensive picture of language learning.

Since Schachter's seminal work, various causes have been proposed to explain the avoidance strategy in the case of phrasal verbs. One of the earliest proposed causes was interference from the mother tongue (e.g., Dagut and Laufer, 1985). Since phrasal verbs represent a unique lexicosyntactic form in Germanic languages, it was proposed that the learners whose mother tongue is non-Germanic (Hebrew-speaking in the case of Dagut and Laufer 1985) will avoid the use of phrasal verbs due to the L1-L2 structural differences. Other studies, however, disregarded this language-specific explanation and resorted to a more universal perspective. For instance, Hulstijn and Maurchena (1989) explained their participants' avoidance of phrasal verbs in terms of universal properties of avoided structures; i.e. semantic difficulty of L2 forms in question. The Dutch learners in their study, for example, avoided the use of figurative phrasal verbs in English when these verbs had literal counterparts in Dutch. Hence, it seems that the tricky nature of multi-word verbs may lead to their avoidance. Following these two significant studies, a number of investigations were carried out in different parts of the world supporting either/both cause(s) and adding other possible explanations, including the negative effect of formal instruction (e.g., Mattar, 2001), the learner's language proficiency level (e.g., Liao \& Fukuya, 2004), the amount/ nature of language exposure (e.g., Imrose, 2008), the intuitive rather than empirical development of ELT textbooks (e.g., Zarifi \& Mukundan, 2014) and psychological factors (e.g., Kleinman, 1977). The following section includes a brief survey of relevant studies in the literature.

\section{Literature Review}

Studies on the avoidance strategy in second language learning investigated the use of various linguistic patterns. Examples from the field of English language learning include the Korean learners' use of relative clauses (Bjers \& Massicotte, 2015), the Thai learners' production of participial reduced relative clauses (Thiamtawan \& Pongpairoj, 2013), the Persian learners' syntax in written production (Moghimizadeh, 2008), the Arab learners' use of subordinating conjunctions and adverbs (Mattar, 2003), and the Hebrew-speaking learners' use of idioms (Laufer, 2000). The literature review section of the present study, however, presents a summary of relevant studies on the avoidance of phrasal verbs, which constitutes the target area of investigation.

Two interesting studies attempted to compare the use of phrasal verbs by learners of English whose native language is Germanic versus those whose mother tongue is non-Germanic. This difference is significant since Germanic languages would share the presence of phrasal verbs with the English language, which should facilitate the learning of English phrasal verbs from a contrastive analysis perspective. The two studies, however, rendered opposing results. Administering a multiple choice task to native Finnish and Swedish-speaking students in Finland, Sjöholm (1995) showed that both Swedes and Fins tend to underuse phrasal verbs, but Fins showed a significantly stronger avoidance tendency. This result is in line with Contrastive Analysis since Swedish is a Germanic language. The study also showed evidence of interlanguage development in the use of phrasal verbs among the Swedes and an influence of the semantic properties of verbs on their acquisition. Kharitonova (2013), however, failed to support the crosslinguistic perspective. In two multiple choice tests, no significant difference was noted in the performance of Norwegian and Russian learners of English despite the fact that Norwegian is a Germanic language while Russian is Slavic. The study highlighted a negative transfer from Norwegian into English as the Norwegian participants tended to use Norwegian-like phrasal verbs with the wrong meaning in English.

Recently, a number of studies have reported relevant findings on the use of phrasal verbs by Asian learners of English. A case in point is You (1999) who examined the avoidance behavior of phrasal verbs by Korean learners. The study addressed two research questions; (1) To what extent do Korean learners of English avoid using phrasal verbs? and (2) If they tend to avoid using phrasal verbs, how can this be explained? The study participants, a total of 217, were divided into four groups including one group for native speakers of English. The other three groups represented Korean learners of English with different backgrounds; those residing in the United States for varied periods versus others residing in Korea, those majoring in English in Korea versus others educated in Korea but enrolled in non-English majors, and adults versus younger children. The participants completed three tests mainly adapted from Dagut and Laufer (1985) and Hultijn and Marchena (1989). The three tests, a verb elicitation, a verb translation and a multiple choice test, assessed the participants' use of phrasal verbs with varying degrees of transparency (i.e., literal, completive and figurative). The results revealed the Korean learners' tendency to avoid using phrasal verbs, particularly the completive and figurative ones which have no parallel structure in Korean. The results also highlighted the role played by other important factors, including the semantic difficulty of phrasal verbs, the learning environment, the educational methodology in Korea and the major field of study. Hence, You (1999) concluded that avoidance, a complex phenomenon, should be explained in terms of both language dependent (e.g., cross-linguistic differences) and language independent (e.g., rule simplification strategy) factors.

Lia and Fukuya (2004) examined the avoidance of phrasal verbs by Chinese learners of English. Employing 85 undergraduate and graduate participants, including native speakers of American English, advanced Chinese learners of English and intermediate Chinese learners of English, the researchers studied the influence of four independent 
variables on the avoidance of phrasal verbs; (1) L1 - L2 structural differences, (2) the semantic complexity of phrasal verbs, (3) the proficiency level of learners and (4) the test effect. The phrasal verbs used for the study purpose were identified at a first stage in which the native speakers completed a multiple choice test of short dialogues. The native speakers' preferences for phrasal verbs over synonymous one-word verbs constituted the basis for assessing the Chinese learners' answers in the multiple choice, recall and translation tests conducted in the second stage. Results of the study highlighted the employment of the avoidance strategy by the intermediate, but not advanced, learners. This was interpreted in terms of significant influence for language proficiency on the avoidance behavior of learners. The unavailability of a parallel structure in Chinese may have led Chinese learners to avoid the use of phrasal verbs. However, increased language proficiency seemed to have neutralized the effect. The study also undermined the role of semantic complexity on the avoidance behavior since the Chinese participants used figurative verbs significantly less than literal verbs only in the translation test. It seems that the Chinese learners' avoidance of figurative phrasal verbs is aggravated by the nature of the translation test which prompts answers using translation equivalents similar to one-word verbs in English.

Saiya (2011) examined the Thai secondary school students' avoidance of phrasal verbs. The participants of the study, consisting of 40 secondary school students who are native speakers of Thai, completed a multiple choice test based on Liao \& Fukuya (2004) to assess the students' avoidance of phrasal verbs. The participants, who were classified into high-proficient and low-proficient learners, had studied English at school for more than 10 years, but had limited exposure to English outside the classroom. The results showed that Thai learners of English generally tend to avoid the use of phrasal verbs in favor of single word equivalents, a finding in line with the L1-L2 structural difference between Thai and English. However, the effect was much more obvious among figurative rather than literal phrasal verbs, which supported the influence of semantic complexity on the avoidance behavior. In contrast to Liao \& Fukuya (2004), no influence was noted for language proficiency on the use of phrasal verbs. Interestingly, Imrose (2008) had also failed to find any influence for language proficiency on the use of phrasal verbs among Thai Master's students at a Teaching English as a Foreign Language Program (TEFL). Contrary to Saiya (2011)'s findings, however, the majority of the 39 TEFL MA participants did not avoid the use of phrasal verbs in the multiple choice test. The results of the two studies can be conciliated in terms of the amount of exposure to the L2 environment. Whereas Saiya (2011)'s participants had limited exposure to English outside the classroom, Imrose's participants who used the phrasal verbs appropriately had considerable exposure to L2 environment as they were speaking English at the workplace.

Kamarudin (2013) examined the use of phrasal verbs by Malaysian learners of English. The study included four types of analysis; (1) a comprehension, multiple choice test of phrasal verbs completed by 480 secondary school students, (2) a questionnaire assessing the common practices of vocabulary teaching in Malaysia and the content of textbooks that was completed by 47 English language teachers, (3) corpus analysis of 24 phrasal verbs in the corpus of English of Malaysian Students (EMAS) and the Bank of English (BoE) Corpus, and (4) an examination of Malaysian school textbooks and learners' dictionaries. The results showed an average understanding of frequent phrasal verbs among Malaysian students, with clear influence of language proficiency on the results. Increased language proficiency led to better understanding and use of phrasal verbs. Other factors were also found relevant to varying degrees, including gender, L1-L2 structural differences and the semantic complexity of phrasal verbs. In addition, the study revealed that school textbooks and learners' dictionaries provide insufficient and inappropriate information on phrasal verbs. In the same vein, Zarifi and Mukundan (2014) commented on the grammatical treatment of phrasal verbs in Malaysian secondary level textbooks as "[overlooking phrasal verbs] as a category of language phenomenon enjoying their own grammatical behavior. There ... appeared to be no guiding principal underlying the selection, presentation and sequencing of different patterns associated with them" (p. 649).

Barekat and Baniasady (2014) investigated the use of Persian undergraduate learners of phrasal verbs and the impact of their use of phrasal verbs on their performance in writing. The study consisted of two parts. First, the 86 participants of English major sat for multiple choice, recall and translation tests to assess their avoidance of phrasal verbs. The scores showed consistent preference for the use of one-word verbs instead of phrasal verbs for the three tests. Second, the participants wrote a composition entitled "If I had a million dollars" in 40 minutes. Examining the writing scores, it was clear that the participants with higher avoidance of phrasal verbs in the three tests performed worse on the writing task than the participants with lower avoidance rates. The study, thus, presented evidence that Persian learners of English tend to avoid using phrasal verbs in their production and this negatively impacts their writing performance. The finding that Persian learners avoid using phrasal verbs in their production was shown in other studies. For example, Sara and Mohammadreza (2013) found evidence of this avoidance among Persian undergraduate and graduate students at both the intermediate and advanced levels. They also showed that avoidance was more common among learners with lower language proficiency and in the case of non-literal phrasal verbs.

In the Arab World, three relevant studies were conducted on the use of phrasal verbs by students majoring in English at university level. The first is Ayadi's (2010) which examined the problem of translating phrasal verbs among third-year Algerian students using two recognition tasks (one paraphrase and the other translation). The second study is AbdulRahman and Abid's (2014) which investigated the use of phrasal verbs among first and fourth-year Omani students using two recognition tasks and one free-writing task. It is worth noting that one of the recognition tasks used on AbdulRahman and Abid (2014) is described in the study as a production task, but the researcher disagrees with this classification. The task requires the participants to fill gaps in sentences using phrasal verbs already provided for the learners in a list. This, thus, seems more of a recognition task than a real production task. The third study was also conducted in Oman by Mahmoud (2015) who examined the use of second year Omani students of phrasal verbs in their 
free writing. The three studies noted the difficulty Arab learners face with phrasal verbs to varying degrees. The applicability of the concept of "avoidance" on the situation in the Arab World was, however, questioned since the participants' poor performance seemed to be better interpreted in terms of ignorance of the structure, passive learning for comprehension and insufficient exposure. This interpretation was, however, inconclusive since the studies relied either on recognition tasks or free writing without a separate task to assess the learners' productive knowledge. In addition, the studies did not control for the participants' possible ignorance of the phrasal verbs used in the tests.

The present study will examine the use of phrasal verbs among Egyptian learners of English as a foreign language (EFL), a new Arabic-speaking population. The study aims to contribute to the abovementioned studies through overcoming the deficiencies in their design. Relevant features of the research design of the present study are (1) the selection of the target phrasal verbs in the study based on the participants' subjective assessment of frequency, (2) the inclusion of a controlled production task which will allow comparing the participants' performance in receptive and productive tasks, on the one hand, and in the production and avoidance tasks, on the other, (3) allowing the participants to complete the avoidance task with phrases in addition to phrasal verbs and single-word verbs, which parallels natural language production, (4) the elicitation of the participants' perspective on their use of phrasal verbs, (5) the implementation of the study among non-English majors and (6) the focus on non-literal verbs. Further details of the research design are provided in the methodology section.

\section{Research Questions}

The present study addresses the following four research questions:

1. To what extent do the Egyptian undergraduate EFL learners accurately use phrasal verbs?

2. To what extend do the Egyptian undergraduate EFL learners avoid producing phrasal verbs?

3. What is the effect of the Egyptian undergraduate EFL learners' increased language exposure on their use of phrasal verbs?

4. What are the Egyptian undergraduate EFL learners' perceptions on the under-representation of phrasal verbs in production?

\section{Methodology}

\subsection{Participants}

The participants of the present study constituted a total of 407 Egyptian undergraduate students enrolled in a private Egyptian university where English is the medium of instruction. The participants, 333 male ( $82 \%$ of the sample) and 74 female ( $18 \%$ of the sample) students, were recruited from three colleges; the College of Engineering, the College of Computer Sciences and the College of Business Administration. Hence, all participants are non-English majors. The participants' age range was between 18 and 28, with an average of 20.7. They had limited exposure to English outside the classroom and had not lived in an English-speaking country for more than 6 months. It was also ensured that neither of their parents is a native speaker of English.

Since the participants' language exposure is an independent variable in the study, the participants were categorized according to two relevant classifications. The first classification is pertinent to the academic year. It is assumed that students enrolled in a higher academic year will represent a higher level of language exposure than their colleagues at lower academic years due to the use of English in all content courses (i.e., Content-Based Instruction). Hence, the participants were classified into two groups; (1) a group representing higher language exposure including students enrolled in the $4^{\text {th }}$ or $5^{\text {th }}$ academic years and (2) a group representing lower language exposure recruited among the $1^{\text {st }}$ and $2^{\text {nd }}$ year students. The higher exposure group in this regard consisted of 210 students whereas the lower exposure group comprised a total of 197 students.

The second classification divided the participants based on their pre-university education; i.e., their school type. The Egyptian educational system allows students to enroll in different types of schools; mainly public (=governmental) and private (=language) schools. In public schools, students study all subjects in Arabic, their native language, while English is studied only during the foreign language classes. In private schools, however, situations are different. Some private schools follow the pattern of public schools but increase the contact hours for English per week whereas the majority of private schools teach most or all subjects in English. This variation in the schooling system proved useful as a second measure for language exposure. The graduates of public schools (a total of 115) represented lower language exposure while the graduates of language schools (a total of 292) represented higher language exposure.

\subsection{Procedure}

Kleinmann (1977) argued "to be able to avoid some linguistic feature presupposes being able to choose not to avoid it; i.e. to use it," (p.97). In other words, it is important to ensure the learners' knowledge of the target structure before assessing his/her avoidance of its use. Learners cannot be described as "avoiding" a target structure of which they are ignorant in the first place. Earlier studies on avoidance, however, neglected this important observation and failed to ensure the participants' knowledge of the phrasal verbs. For instance, Dagut and Laufer (1985) relied on their judgment as language instructors to select the phrasal verbs used in their study. Saiya (2011) used the same phrasal verbs in Liao and Fukuya (2004) which were mainly selected based on the native speakers' judgment. On the other hand, Barekat and Baniasady (2014) chose their phrasal verbs from a reference book including a 1,000 well-known phrasal verbs. Such 
studies were, thus, criticized for failing to ensure that the participants' performance reflects the phenomenon of avoidance since the results may simply reflect the learners' ignorance of the phrasal verbs.

To avoid this deficiency, the present study assessed the Egyptian learners' knowledge of the target phrasal verbs through a pre-study survey. A list of 180 non-literal (=idiomatic) phrasal verbs was selected for an initial survey. The verbs were judged by the researcher, who taught English in the Arab World for more than 20 years, as common among the target sample. The list was divided into two surveys, each distributed among 30 first-year students. Every survey thus targeted 90 phrasal verbs which were included in sentences and provided with Arabic translation equivalents. The participants were asked to read through the sentences and the translation equivalents and rank the underlined phrasal verbs on a 5-point Likard scale to assess how frequently the participants read or hear the given phrasal verbs. Analyzing the answers of the 60 participants, the researcher selected 45 phrasal verbs to be used in the study. All the selected verbs were ranked as very frequent or frequent by a minimum of $70 \%$ of the participants.

The second preparation stage for the study was the writing of the tasks. A 10-page assignment was prepared for the study. The first page included instructions for the study tasks. It also ensured the participants that their answers will remain confidential and that they will only be used for research purposes. In fact, the participants were not required to supply their names on the assignments. The second page of the assignment required the participants to include demographic information; mainly, their university major, age, gender, academic year of study, nationality and their preuniversity schooling. The participants were also required to indicate if they had lived in an English-speaking country for more than 6 months and if either of their parents is a native speaker of English. Positive responses to these two questions led to exclusion of the study sample.

Pages $3-7$ on the assignment included three study tasks which were based on the 45 non-literal phrasal verbs selected from the pre-study survey. The first task was a recognition task that aimed to assess the participants' receptive knowledge. In this task, the participants were provided with 15 sentences, each of which with an underlined phrasal verb, and were requested to explain the meaning of the phrasal verbs in Arabic or English. For example, the learners would read the sentence "I will run out of shampoo soon" and write the meaning of the underlined phrasal verb in the language of their choice. Two remarks need to be made here. First, the researcher checked all sentences to ensure that they cannot be used to disambiguate the meaning of the phrasal verbs. Second, the participants were given the freedom to write in either language to facilitate the task. The purpose of the task was to assess the learners' understanding of the phrasal verbs regardless of their preferred language.

The second and third tasks included controlled production. In the second task, the participants were provided with 15 sentences, each with a missing phrasal verb. The participants were required to read through the sentences and supply the missing phrasal verbs whose Arabic translation equivalents were provided underneath the sentences. The missing phrasal verbs were again selected from the initial 45 non-literal cohort but were different than the ones included in the first recognition task. The purpose of this task was to assess the participants' productive knowledge of these frequent phrasal verbs. The third task was to measure the participants' employment of the avoidance strategy when given the freedom to express their thoughts using their preferred lexis. The task targeted the remaining 15 phrasal verbs of the initial cohort. The participants were required to read through 15 sentences with missing parts. They were asked to complete the missing parts with their preferred choice of phrasal verbs, single-word verbs or phrases taking into consideration the Arabic translation equivalents provided. The sentences and Arabic equivalents would always allow for completion with a phrasal verb or a single-word verb, and sometimes with phrases as well. It is worth mentioning that the Arabic equivalents in the second and third tasks were not necessarily lexicalized. The meaning of the missing phrasal verbs was provided using one, two or more words as deemed appropriate.

Pages $8-10$ of the assignment required the participants to read through 10 reasons for the under-representation of phrasal verbs in Egyptian learners' production and rank them along a 5-point Likard scale to indicate their (dis)agreement with the reasons. The purpose of this section was to elicit the participants' perceptions on their use of phrasal verbs. The 10 reasons, provided for the participants in both English and Arabic, were as follows:

1. Phrasal verbs are difficult to understand.

2. Phrasal verbs are difficult to produce.

3. Phrasal verbs are not frequent in English.

4. Phrasal verbs are more commonly used among the youth than older generations. Hence, English language learners avoid using phrasal verbs.

5. Using single-word verbs demonstrates more mastery of the English language than using phrasal verbs. Hence, English language learners avoid using phrasal verbs.

6. Phrasal verbs are more common in informal and slang English, so English language learners avoid using them.

7. English language teachers do not pay enough attention to phrasal verbs in class.

8. English language textbooks do not include enough information or practice on the use of phrasal verbs.

9. The Arabic language does not include phrasal verbs, so Arab learners find it difficult to learn phrasal verbs in English.

10. Egyptian learners of English do not practice the English language in a natural context (e.g., with native speakers or foreigners).

As shown in the list, the reasons in the assignment assessed the participants' knowledge of phrasal verbs (Reasons $1 \&$ 2), their awareness of the importance and use of phrasal verbs in natural English (Reasons 3, 4, 5 \& 6), the formal instruction of phrasal verbs in schools (Reasons $7 \& 8$ ), the participants' awareness of the crosslinguistic difference 
between Arabic and English (Reason 9) and the significance of practicing the language in a natural context (Reason 10). In addition to these reasons, the participants were requested to add any other reasons they find relevant based on their experience.

The administration of the assignment was carried out by the researcher. After seeking course instructors' and students' permission to administer the assignment, the researcher explained the instructions in Arabic to ensure that all the participants understand the tasks. Examples were also provided for every type of task. Although the language used in the test sentences was reviewed by 4 language instructors and judged as appropriate for the participants' level, the researcher still announced to the participants that she would welcome any queries. This was to ensure that the participants understand the sentences, and hence their answers will reflect their knowledge of the target phrasal verbs. The participants were allowed to complete the tasks at their own pace. The participants thus varied in their completion times between 25 and 40 minutes.

\section{Results}

The results section is classified in accordance with the research questions.

Question (1) To what extent do the Egyptian undergraduate EFL learners accurately use phrasal verbs?

The participants' knowledge of phrasal verbs was measured along the two dimensions of receptive and productive knowledge. The receptive knowledge was measured using Task (1) on the study assignment which required the participants to explain the meaning of 15 phrasal verbs in English or Arabic. The participants' answers were classified into right and wrong answers and the frequency and percentages of the answers indicate relatively good receptive knowledge. As shown in Table (1) and Figure (1), the first and second-year participants provided correct answers with a percentage of $83.2 \%$ while the fourth and fifth-year participants' correct answers stood at $78.6 \%$.

Table 1. The participants' receptive knowledge

\begin{tabular}{|c|c|c|c|c|c|c|c|}
\hline Year & Answers & Frequency & Percent & Min. & Max. & Mean & SD \\
\hline $\begin{array}{l}1^{\text {st }} \& \\
2^{\text {nd }}\end{array}$ & Wrong Answer & 33 & 16.8 & & & & \\
\hline \multirow[t]{2}{*}{ Year } & Right Answer & 164 & 83.2 & .53 & 1.00 & .8386 & .09707 \\
\hline & Total & 197 & 100.0 & & & & \\
\hline \multirow{3}{*}{$\begin{array}{l}4^{\text {th }} \& \\
5^{\text {th }} \text { year }\end{array}$} & Wrong Answer & 45 & 21.4 & & & & \\
\hline & Right Answer & 165 & 78.6 & .50 & 1.00 & .8487 & .11121 \\
\hline & Total & 210 & 100.0 & & & & \\
\hline
\end{tabular}

As for the productive knowledge, it was measured using Task (2) on the study assignment. In this task, the participants were required to complete missing gaps in sentences with appropriate phrasal verbs provided that the phrasal verbs conveyed the same meaning as the Arabic translation equivalents written below the sentences. The participants' answers were marked and the frequency and percentages of the correct answers demonstrated extremely poor productive knowledge. As shown in Table (2) and Figure (1), the participants' correct answers fell below one third (average 30.7\%) with the first and second-year participants scoring $22.8 \%$ and the fourth and fifth-year participants scoring $38.6 \%$.

Table 2. The participants' productive knowledge

\begin{tabular}{|c|c|c|c|c|c|c|c|}
\hline Year & Answers & Frequency & Percent & Min. & Max. & Mean & SD \\
\hline \multirow{4}{*}{$\begin{array}{l}1^{\text {st }} \& \\
2^{\text {nd }} \\
\text { Year }\end{array}$} & Wrong Answer & 152 & 77.2 & & & & \\
\hline & & & & & & & \\
\hline & Right Answer & 45 & 22.8 & .50 & .93 & .6948 & .08768 \\
\hline & Total & 197 & 100.0 & & & & \\
\hline \multirow{3}{*}{$\begin{array}{l}4^{\text {th }} \& \\
5^{\text {th }} \text { year }\end{array}$} & Wrong Answer & 129 & 61.4 & & & & \\
\hline & Right Answer & 81 & 38.6 & .50 & .97 & .7208 & .10584 \\
\hline & Total & 210 & 100.0 & & & & \\
\hline
\end{tabular}




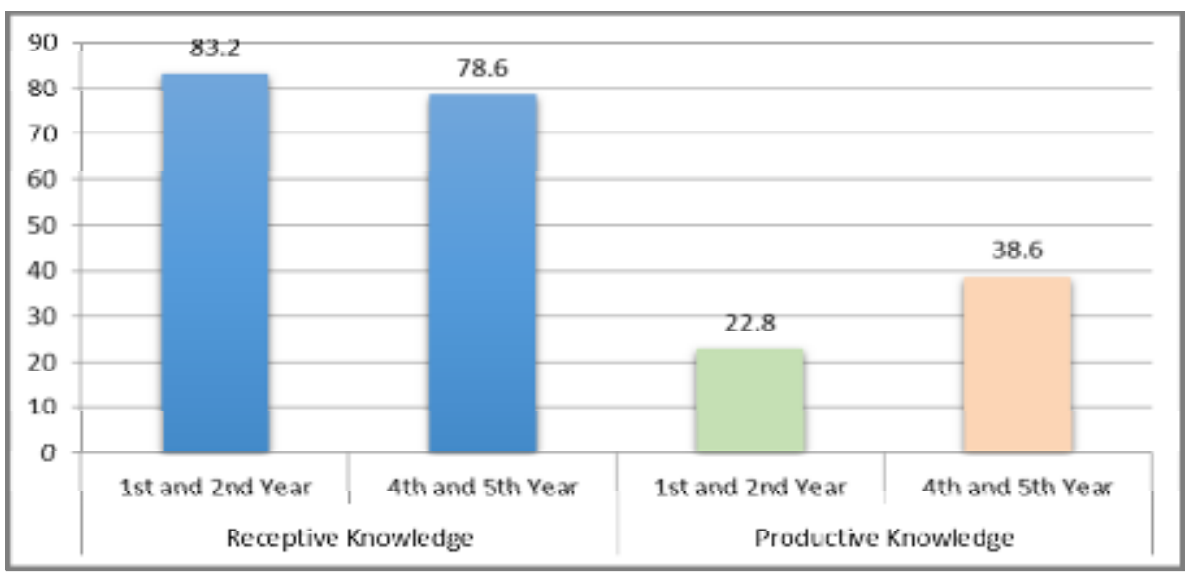

Figure 1. The participants' receptive and productive knowledge

Question (2): To what extent do the Egyptian undergraduate EFL learners avoid producing phrasal verbs?

The second question aimed to measure the participants' employment of the avoidance strategy with phrasal verbs. The question was addressed in Task (3) of the study assignment in which the participants were required to complete gaps in sentences with appropriate phrasal verbs, single-word verbs or phrases. The participants' answers had to match the Arabic translation equivalents provided below the sentences. The participants' answers were marked and classified into three categories; (1) wrong answers, (2) right answers demonstrating avoidance (i.e., single-word verbs or phrases) and (3) right answers with phrasal verbs. The participants' use of the phrasal verbs came absolutely poor as shown in Table (3) and Figure (2). While the participants supplied single-word verbs or phrases in $62.9 \%$ of their answers for the first and second-year participants and $64.8 \%$ for the fourth and fifth-year participants, their use of phrasal verbs stood at $0.5 \%$ for the first group and $3.3 \%$ for the latter group.

Table 3. The participants' employment of the avoidance strategy

\begin{tabular}{|c|c|c|c|c|c|c|c|}
\hline Year & Answers & Frequency & Percent & Min. & Max. & Mean & SD \\
\hline $\begin{array}{l}1^{\text {st }} \& \\
2^{\text {nd }}\end{array}$ & Wrong Answer & 72 & 36.5 & & & & \\
\hline \multirow[t]{3}{*}{ Year } & Avoidance & 124 & 62.9 & .50 & 1.27 & .8156 & .16665 \\
\hline & Phrasal Verb & 1 & .5 & & & & \\
\hline & Total & 197 & 100.0 & & & & \\
\hline \multirow{4}{*}{$\begin{array}{l}4^{\text {th }} \& \\
5^{\text {th }} \text { year }\end{array}$} & Wrong Answer & 67 & 31.9 & & & & \\
\hline & Avoidance & 136 & 64.8 & .50 & 1.40 & .8641 & .19552 \\
\hline & Phrasal Verb & 7 & 3.3 & & & & \\
\hline & Total & 210 & 100.0 & & & & \\
\hline
\end{tabular}

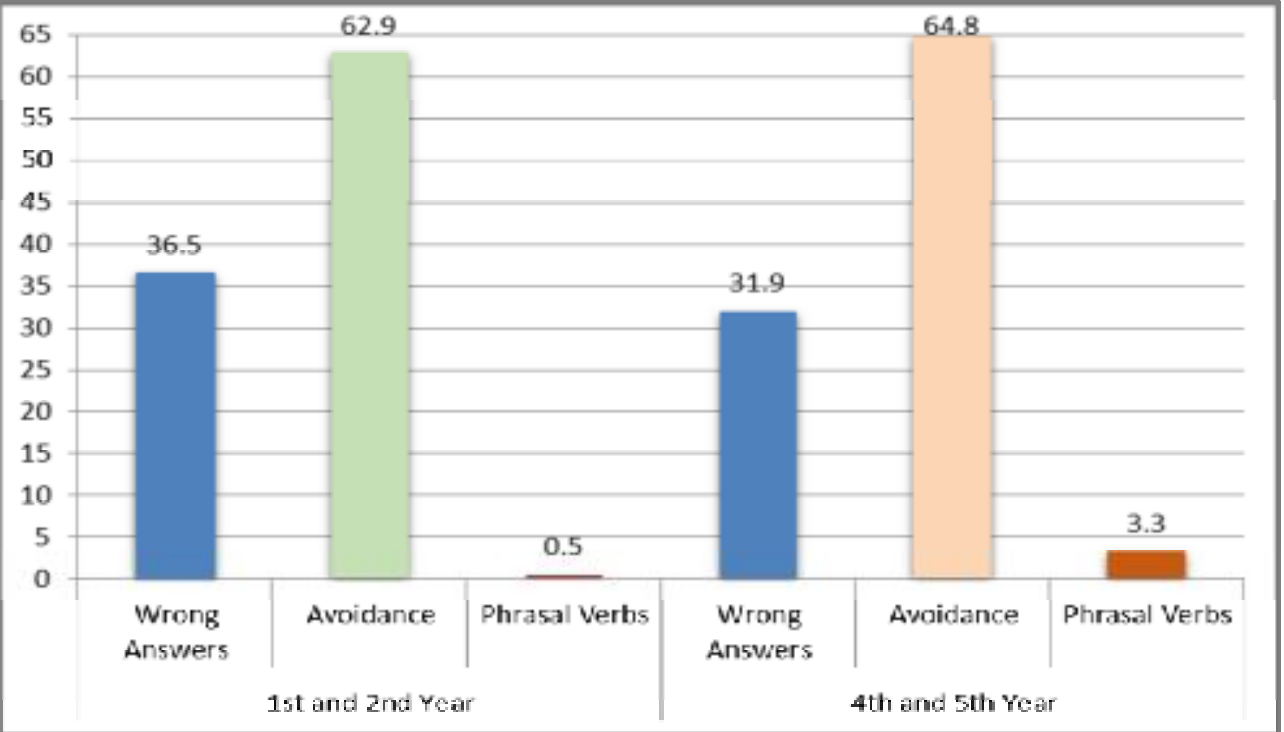

Figure 2. The participants' employment of the avoidance strategy 
Question (3): What is the effect of the Egyptian undergraduate EFL learners' increased language exposure on their use of phrasal verbs?

The third study question was set to assess the influence of increased language exposure on the use of phrasal verbs. The increased language exposure was assessed using two measures in the present study; (1) comparing the performance of first and second-year participants versus the fourth and fifth-year participants with the latter representing increased language exposure, and (2) comparing the performance of the public-school participants versus the language-school participants with the latter again representing increased language exposure. The two comparisons were conducted using a 2-tailed T-Test. Regarding the first comparison, Table (4) and Figure (3) show the effect of increased language exposure on the use of phrasal verbs with reference to the academic year. While no statistically significant difference was observed between the two study groups in terms of receptive knowledge (Task 1), the fourth and fifth-year participants outperformed the first and second-year participants at the productive knowledge (Task 2) with a significance of 0.007 . A similar significance of 0.007 was noted at the employment of avoidance (Task 3) with the fourth and fifth-year participants producing more phrasal verbs and, hence, employing the avoidance strategy to a lesser extent.

Table 4. T-Test results - The effect of increased language exposure for the academic year

\begin{tabular}{llllllll}
\hline Item & $\begin{array}{l}\text { Academic } \\
\text { Year }\end{array}$ & Mean & $\mathbf{t}$ & $\mathbf{d f}$ & Sig & $\begin{array}{l}\text { Mean } \\
\text { Difference }\end{array}$ & SD \\
\hline $\begin{array}{l}\text { Receptive } \\
\text { Knowledge }\end{array}$ & $1^{\text {st }} \& 2^{\text {nd }}$ & .8386 & -.978 & 405 & .328 & -.01015 & .01038 \\
& $4^{\text {th }} \& 5^{\text {th }}$ & .8487 & & & & & \\
\hline $\begin{array}{l}\text { Productive } \\
\text { Knowledge }\end{array}$ & $1^{\text {st }} \& 2^{\text {nd }}$ & .6948 & -2.693 & 405 & .007 & -.02604 & .00967 \\
& $4^{\text {th }} \& 5^{\text {th }}$ & .7208 & & & & & \\
$\begin{array}{l}\text { Use of Phrasal } \\
\begin{array}{l}\text { Verbs in the } \\
\text { Avoidance } \\
\text { Task }\end{array}\end{array} 1^{\text {st }} \& 2^{\text {nd }}$ & .8156 & & & & & \\
\hline
\end{tabular}

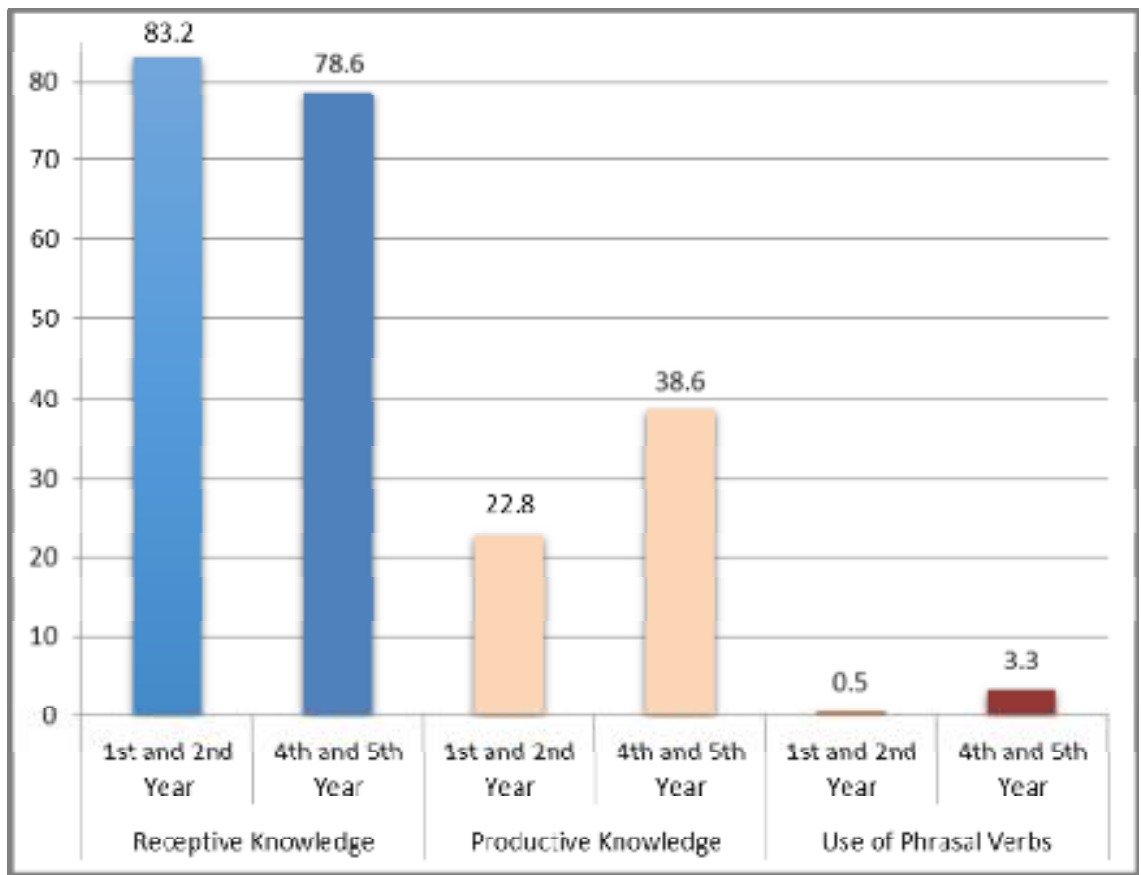

Figure 3. The effect of increased language exposure for the academic year

The second measure of increased language exposure in the study is related to pre-university education. Table (5) and Figure (4) show the effect of increased language exposure with reference to school type. Similar to the academic year, the school type revealed an advantage for increased language exposure. The language-school graduates, representing increased language exposure, performed significantly better than the public-school graduates both at the receptive knowledge and productive knowledge at 0.005 . As for the avoidance strategy, the language-school graduates employed the strategy significantly less than the public-school graduates at 0.006 . 


\begin{tabular}{|c|c|c|c|c|c|c|c|}
\hline Item & $\begin{array}{l}\text { Academic } \\
\text { Year }\end{array}$ & Mean & $\mathbf{t}$ & df & Sig & $\begin{array}{l}\text { Mean } \\
\text { Difference }\end{array}$ & SD \\
\hline $\begin{array}{l}\text { Receptive } \\
\text { Knowledge }\end{array}$ & $\begin{array}{l}\text { Public } \\
\text { Language }\end{array}$ & $\begin{array}{l}.8206 \\
.8530\end{array}$ & -2.837 & 405 & .005 & -.03239 & .01142 \\
\hline $\begin{array}{l}\text { Productive } \\
\text { Knowledge }\end{array}$ & $\begin{array}{l}\text { Public } \\
\text { Language }\end{array}$ & $\begin{array}{l}.6864 \\
.7168\end{array}$ & -2.836 & 405 & .005 & -.03040 & .01072 \\
\hline $\begin{array}{l}\text { Use of Phrasal } \\
\text { Verbs in the } \\
\text { Avoidance } \\
\text { Task }\end{array}$ & $\begin{array}{l}\text { Public } \\
\text { Language }\end{array}$ & .8006 & -2.785 & 405 & .006 & -.05581 & .02004 \\
\hline
\end{tabular}

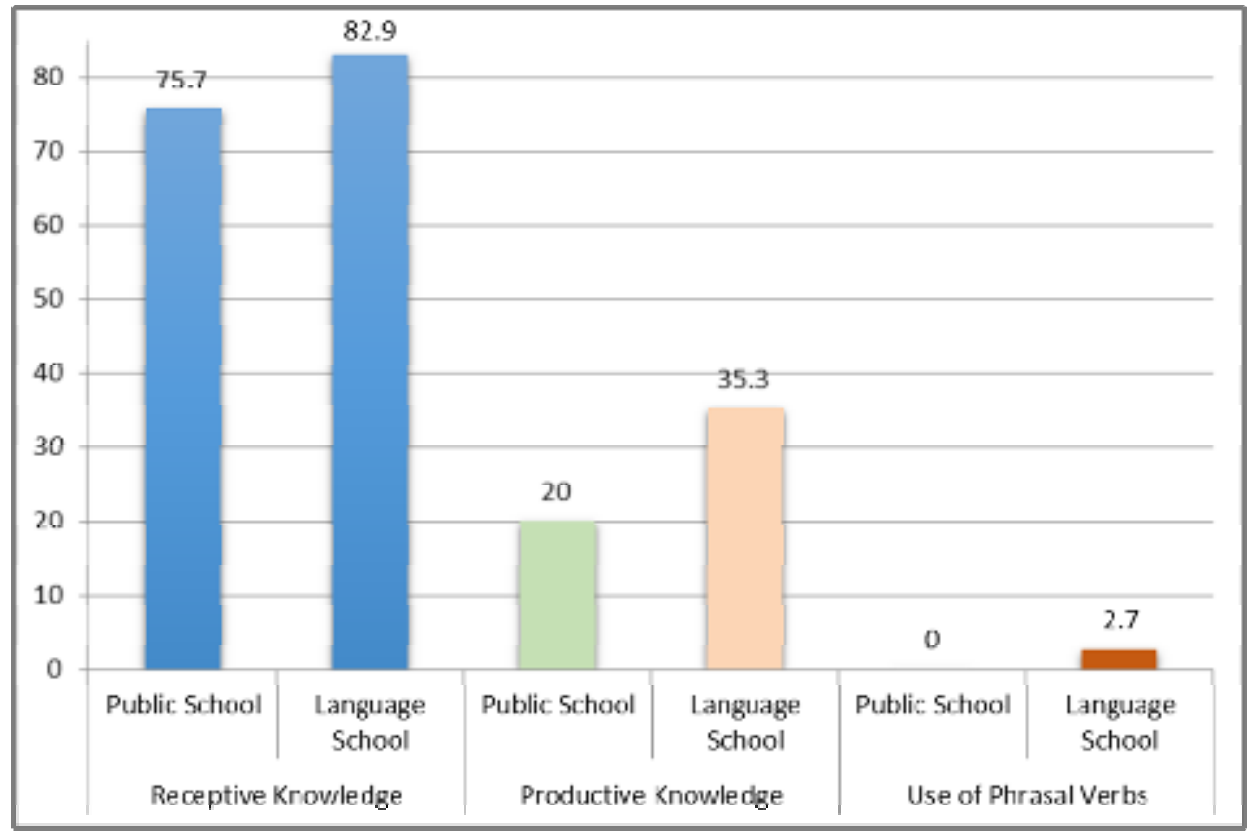

Figure 4. The effect of increased language exposure for the school type

Question (4): What are the Egyptian undergraduate EFL learners' perceptions on the under-representation of phrasal verbs in production?

The last research question aimed to elicit the participants' perceptions on their poor use of phrasal verbs. The participants were requested to express their degree of (dis)agreement with 10 reasons why Egyptian learners underuse phrasal verbs and were also allowed to add their own reasons. Examining the participants' ratings, it is noted that more than $70 \%$ of the participants agreed that the main cause for their poor use of phrasal verbs is their lack of practice within a natural context. This was the cause scoring the highest percentage of agreement. More than half of the participants criticized the formal instruction at schools as 58.24\% believed that English language teachers do not pay enough attention to phrasal verbs and $53.56 \%$ believed that the English language textbooks lack sufficient information/ practice on phrasal verbs.

Analyzing the remaining ratings reveal further interesting findings. The participants' ratings reflect misconceptions regarding the use of phrasal verbs. Almost $50 \%$ of the participants believe that phrasal verbs are more commonly used among the youth and are thus avoided by language learners. Besides, more than $50 \%$ believe that using single-word verbs reflects better mastery of the English language and that phrasal verbs are not used in formal or academic language. It is worth noting though that more than three quarters of the participants expressed awareness of the high frequency of phrasal verbs in English. In addition, some participants supported the influence of cross-linguistic differences or the complex nature of phrasal verbs. Almost two fifths of the participants thought that phrasal verbs are difficult to understand (42.51\%) and produce (39.81\%). In addition, 46.93\% agreed that the absence of phrasal verbs in Arabic may contribute to the underrepresentation of phrasal verbs in the Egyptian learners' production.

Finally, 30 participants provided additional causes. Half the causes represented criticism of the formal instruction offered in schools including the poor proficiency level of teachers and the use of unsuccessful teaching methods. Almost one third believed that their poor knowledge is caused by the lack of practice in a natural context. The remaining answers referred to the difficult nature of phrasal verbs, including their polysemous nature and the need to memorize the particles. 
Table 6. The participants' perceptions on the under-representation of phrasal verbs in the Egyptian learners' production

\begin{tabular}{clllll}
\hline Reason \# & Strongly Agree & Agree & Disagree & $\begin{array}{l}\text { Strongly } \\
\text { Disagree }\end{array}$ & Don't Know \\
\hline $\mathbf{1}$ & $10.81 \%$ & $31.70 \%$ & $41.77 \%$ & $13.02 \%$ & $2.70 \%$ \\
\hline $\mathbf{2}$ & $9.34 \%$ & $30.47 \%$ & $41.52 \%$ & $15.23 \%$ & $3.44 \%$ \\
\hline $\mathbf{3}$ & $5.41 \%$ & $18.18 \%$ & $39.07 \%$ & $25.80 \%$ & $11.55 \%$ \\
\hline $\mathbf{5}$ & $17.69 \%$ & $31.45 \%$ & $15.97 \%$ & $13.51 \%$ & $21.38 \%$ \\
\hline $\mathbf{6}$ & $23.59 \%$ & $28.50 \%$ & $27.52 \%$ & $11.06 \%$ & $9.34 \%$ \\
\hline $\mathbf{7}$ & $21.87 \%$ & $36.36 \%$ & $22.11 \%$ & $8.35 \%$ & $11.30 \%$ \\
\hline $\mathbf{8}$ & $29.98 \%$ & $28.26 \%$ & $26.54 \%$ & $8.11 \%$ & $7.13 \%$ \\
\hline $\mathbf{9}$ & $21.60 \%$ & $30.96 \%$ & $22.60 \%$ & $14.25 \%$ & $9.58 \%$ \\
\hline $\mathbf{1 0}$ & $39.56 \%$ & $25.55 \%$ & $21.62 \%$ & $14.00 \%$ & $17.44 \%$ \\
\hline
\end{tabular}

\section{Discussion}

The present study addressed four research questions. The first question aimed to assess the participants' lexical knowledge of phrasal verbs. To this end, the participants' answers to a recognition task and a controlled production task were analyzed. In accordance with the general pattern in vocabulary studies, the participants demonstrated better receptive than productive knowledge with an average percentage of correct answers of $80.9 \%$ for the receptive and $30.7 \%$ for the productive. Despite the expected pattern, the discrepancy between the receptive and productive knowledge is notably large. The participants' knowledge of the phrasal verbs seems to be generally limited to understanding language input but has not developed enough to enable the participants to use phrasal verbs in their speaking/writing. This reflects a focus on passive learning for comprehension which fails to support production. This observation supports similar findings with Omani learners in Ayadi and AbdulRahman (2014) and Mahmoud (2015).

In addition to the large discrepancy, the participants' performance is unsatisfactory due to the selection method of the phrasal verbs under investigation. As noted earlier, the phrasal verbs in the present study were selected based on a prestudy survey measuring the subjective frequency of the verbs among the participants. It is, thus, disappointing to note such poor performance with verbs ranked as frequently encountered by the participants themselves. This raises a serious concern regarding their knowledge of other phrasal verbs in English. It is worth mentioning in this context that the results of the pre-study survey were notably poor. Some phrasal verbs that were judged as frequent among the target population by the researcher based on her teaching experience received very low frequency ratings (e.g., $10 \%$ for pay off and wrap up, 7\% for cater for and rule out and 3\% for drag on and grow apart). Such poor performance casts doubt on the results of earlier studies (e.g., Barekat and Baniasady, 2014; Liao and Fukuya, 2004; Dagut and /Laufer, 1985) which did not employ subjective frequency counts.

Based on earlier studies, it is worth highlighting three factors that may have particularly contributed to the Egyptian learners' poor performance on the study tasks. First, the present study focused on non-literal phrasal verbs, which have proved the most difficult for English language learners in a number of studies (e.g., Saiya, 2011; You, 1999). Second, contrary to earlier studies in the Arab World (i.e., Mahmoud, 2015; AbdulRahman and Abid, 2014; Ayadi, 2010), the present study employed non-English majors as the study participants. This major difference may have contributed to the current results. This is in line with You's (1999) findings of the influence of university major on the acquisition of phrasal verbs. Finally, the Egyptian learners in the present study learn English in a foreign language context. Learners, living in Alexandria, Egypt, have limited exposure, if any, to English outside the classroom and are mainly taught by Arabic-speaking teachers. This is different than other parts of the Arab World such as the Gulf Region with a relatively large population of English-speaking expatriates and a notable percentage of English-speaking instructors at Englishmedium universities.

The second study question was set to assess the extent of the participants' tendency to avoid the use of phrasal verbs in their production. To this end, the participants completed missing parts in sentences with phrasal verbs, single-word verbs or phrases. Excluding the participants' wrong answers, which represented almost a third of the responses, the remaining correct answers were classified into phrasal verbs or non-phrasal verbs. The participants' use of phrasal verbs in this task was extremely limited as it stood at an average of $1.9 \%$ whereas non-phrasal verbs accounted for $63.85 \%$. Considering the low percentage of correct answers on the productive knowledge task (only 30.7\%), the dramatically limited use of phrasal verbs at Task (3) can be interpreted in terms of both poor productive knowledge and L1-L2 structural differences. As noted earlier, the participants' productive knowledge of phrasal verbs is notably low, which must have negatively contributed to their use of phrasal verbs in Task (3). However, the poor productive knowledge cannot be the only cause behind this incredibly limited use of phrasal verbs since the participants' use of phrasal verbs fell from $30.7 \%$ in the productive task to $1.9 \%$ in the avoidance task. Cross-linguistic differences between the Arabic and English languages could have thus partially contributed to the result.

This interpretation of results comes in line with earlier studies (e.g., You, 1999) that explain the avoidance phenomenon in terms of both language dependent (e.g., cross-linguistic differences) and language independent (e.g., passive learning for comprehension) factors. The present interpretation does not, however, agree with earlier studies in the Arab World (e.g., Mahmoud, 2015) that overrule the applicability of the avoidance phenomenon to the situation in the Arab World. Explaining the under-representation of phrasal verbs in Arab learners' production in terms of ignorance of the structure, 
passive learning for comprehension and insufficient exposure seems to hold part of the truth, but cannot be solely used to interpret the present study results. Having controlled for the participants' ignorance of the structure using the prestudy survey, the present study observes the impact of passive learning for comprehension but also notes that it cannot be solely responsible for the learners' avoidance of the phrasal verbs in Task (3). Cross-linguistic factors are thus offered as another contributing factor.

As for the impact of language exposure, the present study supports earlier findings revealing the positive influence of increased language exposure on the use of phrasal verbs (e.g., AbdulRahman and Abid, 2014; Saiya, 2011 versus Imrose, 2008). A positive influence for increased language exposure was noted with reference to the academic year as the fourth and fifth-year participants significantly outperformed the first and second-year participants at 0.007 at both the productive knowledge and at the use of the phrasal verbs in the avoidance task. This positive influence was further confirmed considering pre-university education. The language-school participants scored significantly higher than the public-school participants at 0.005 at the receptive/productive knowledge and used more phrasal verbs in the avoidance task at 0.006 . It must be noted though that the influence of increased language exposure was not very strong. For example, language-school graduates outperformed the public-school graduates with a difference of $15 \%$ in the productive task and $2 \%$ in the use of phrasal verbs in the avoidance task. A higher difference is expected to reflect long years of exposure of pre-university education. This raises concerns regarding the quality of input in language education and calls for the intervention of effective formal instruction to master such formal language features.

Interestingly, the participants' perceptions regarding the under-representation of phrasal verbs in their production supports the multi-faceted explanation offered in the present study. A great deal of participants believed that their poor use of phrasal verbs can be interpreted in terms of a variety of factors including lack of practice in a natural context, ineffective language instruction and the difficult nature of phrasal verbs. These factors match earlier findings (e.g., Kamarudin, 2013; Mattar, 2001; Hulstijn \& Mauchena, 1989). Examining the participants' perceptions though reveals an additional contributing factor which is lack of proper awareness of the target structure. For example, a relatively large number of participants wrongly believed that phrasal verbs are more commonly used among the youth, do not appear in formal or academic language and that the use of single-word verbs shows better mastery of English. These misconceptions must have hindered the participants' learning/ use of phrasal verbs.

\section{Conclusion}

The present study lends support to earlier studies highlighting the difficulty phrasal verbs represent for English language learners (e.g., Kamarudin, 2013; Saiya, 2011; Liao \& Fukuya, 2004). The difficulty is particularly highlighted in the present study because the phrasal verbs under investigation were selected based on a pre-study survey assessing the participants' subjective knowledge of the frequency of the verbs. Despite selecting verbs that were ranked as frequent by the majority of the participants, the learners' knowledge of the verbs, particularly the productive knowledge, proved unsatisfactory. This came in line with earlier studies in the Arab World (e.g., Mahmoud, 2015) that partly contributed the noted difficulty to passive learning for comprehension.

In addition, the present study confirmed the observation that English language learners tend to avoid the use of phrasal verbs in production (e.g., Barekat \& Baniasady, 2014; Dagut \& Laufer, 1985). The causes noted in the study include a mixture of cross-linguistic differences, poor productive knowledge and limited language exposure. This interpretation lends support to a multi-faceted model explaining the under-representation of phrasal verbs in English language learners' speaking/ writing as suggested in some earlier studies (e.g., Kamarudin, 2013; You, 1999). Analyzing the brief survey distributed to the participants also supports the multi-faceted model with a large number of participants contributing their poor knowledge of phrasal verbs to lack of practice in a natural context, ineffective instruction and the complex nature of phrasal verbs. The participants' responses in the survey, however, show that their limited use of phrasal verbs may also be contributed to misconceptions about the use of the verbs in natural English.

In conclusion, the present study highlights that the under-representation of phrasal verbs in EFL learners' production is an outcome of a multitude of factors. The present study has pointed out three main relevant factors; (1) L1-L2 structural differences, (2) passive learning for comprehension, and (3) limited language exposure. Further studies are needed to explore additional variables, particularly with reference to the role of formal instruction, the learners' awareness of the use of phrasal verbs in natural English and the learning environment. The present study also calls for a revision of the English language programs in Egypt. The students' long years of English language learning, even with increased contact hours in the case of private schooling, do not seem to have resulted in satisfactory results in the case of the learning of phrasal verbs.

\section{References}

Abdul Rahman, Z.A. \& Abid, R. Z. (2014). Rarity or non-existence of phrasal verbs in the written discourse of Omani student-teachers of English. SAGE Open, 4(4), 1-10. DOI: 10.1177/2158244014556988

Ayadi, A. (2010). Lexical translation problems: The problem of translating phrasal verbs. The case of third year LMD learners of English. Unpublished MA dissertation at Mentouri University, Algeria. Available at: http://bu.umc.edu.dz/theses/anglais/AYA1194.pdf 
Barekat, B. \& Baniasady, B. (2014). The impact of phrasal verb avoidance on the writing ability of the university EFL learners. In ElSevier - Procedia - Social and Behavioral Sciences, 98, 343-352: The International Conference on Current Trends in ELT, Urmia University, Iran (20-22 May, 2013).

Biber, D., Johansson, S., Leech, G., Conrad, S., and Finegan, E. (1999). Longman grammar of spoken and written English. Harlow, England: Longman.

Bjers, M. J. \& Massicotte, B. A. (2015). Avoidance of the relative clause by Korean learners of English. Linguistic Portfolios, 4, 35-43, Available at: http://repository.stcloudstate.edu/stcloud_ling/vol4/iss1/4

Dagut, M. \& Laufer, B. (1985). Avoidance of phrasal verbs - a case for contrastive analysis. Studies in Second Language Acquisition, 7, 73-79.

Ellis, R. (1986). Understanding second language acquisition. Oxford: Oxford University Press.

Erman, B. \& Warren, B. (2000). The idiom principle and the open choice principle. Text, 20 (1), $29-62$.

Hulstijn, J. H., \& Marchena, E. (1989). Avoidance: Grammatical or semantic causes? Studies in Second Language Acquisition, 11, 241-255.

Imrose, V. (2008). The use of phrasal verbs by Thai MA TEFL students of Thammasat University. Unpublished MA research paper at Thammasat University, Thailand.

Kamarudin, R. (2013). A study on the use of phrasal verbs by Malaysian learners of English. Unpublished PhD dissertation at the University of Birmingham, UK. Available at:

http://etheses.bham.ac.uk/4504/1/Kamarudin13PhD1.pdf

Kharitonova, A. (2013). Lexical transfer and avoidance in the acquisition of English phrasal verbs: Evidence from Russian and Norwegian learners of English. Unpublished MA dissertation at the University of Oslo, Norway. Available at: https://www.duo.uio.no/bitstream/handle/10852/37028/KharitonovaMaster.pdf?sequence=1

Kleinmann, H. H. (1977). Avoidance behavior in adult second language acquisition. Language Learning, 27 (1), $93-$ 107.

Laufer, B. (2000). Avoidance of idioms in a second language: The effect of L1-L2 degree of similarity. Studia Linguistica, 54(2), 186-196.

Laufer, B. \& Eliasson, S. (1993). What causes avoidance in L2 learning: L1-L2 difference, L1-L2 similarity, or L2 complexity? Studies in Second Language, 15, 35-48.

Liao, Y., \& Fukuya, Y. J. (2004). Avoidance of phrasal verbs: The case of Chinese learners of English. Language Learning, 54, 193-226.

Mahmoud, A. (2015). Under-representation of phrasal verbs in EFL university students' free writing. International Journal of English and Education, 4(1), 261-268.

Mattar, H. (2003). Is avoidance ruled out by similarity? The case of subordinating conjunctions/adverbs in English and Arabic. Poznan Studies in Contemporary Linguistics, 38, 103-115

Mattar, H. (2001). Is avoidance a reflection of mother tongue interference? The case of the present perfect tense. International Journal of Arabic-English Studies, 2(2), 141-155.

Moghimizadeh, R.P. (2008). The study of syntactic avoidance on the written production of Persian university students majoring in teaching English as a foreign language. Unpublished $\mathrm{PhD}$ dissertation at Universiti Sains Malaysia, Pinang, Malaysia. Available at: http://eprints.usm.my/id/eprint/10400

Saiya, C. (2011). Avoidance of phrasal verbs by M.6 students at T.N. School. Unpublished Master's research paper at Thammasat University, Thailand. Available at: http://digi.library.tu.ac.th/thesis/lg/0602/title-appendix.pdf

Sara, H. \& Mohammadreza, T. (2013). Study on avoidance behavior among Persian EFL learners: Phrasal verbs in focus. Greener Journal of Educational Research, 3(6), 238-248.

Schachter, J. (1974). An error in error analysis. Language Learning, 24, 205-214.

Schmitt, N. (2010). Researching vocabulary: A vocabulary research manual. London: Palgrave Macmillan.

Sjöholm, K. (1995). The influence of crosslinguistic, semantic, and input factors on the acquisition of English phrasal verbs: A comparison between Finnish and Swedish learners at an intermediate and advanced Level. Abo, Finland: Abo Akademy University.

Thiamtawan, S., \& Pongpairoj, N. (2013). Avoidance of the use of English participial reduced relative clauses among L1 Thai learners. LEARN Journal, 1(2), 12-34.

Willis, D. (2003). Rules, patterns and words: Grammar and lexis in English language teaching. Cambridge: Cambridge University Press

You, Y. (1999). Avoidance phenomena of phrasal verbs by Korean learners of English. English Teaching, 54(3), 135155.

Zarifi, A. \& Mukundan, J. (2014). Grammatical presentation of phrasal verbs in ESL textbooks. Social Sciences and Humanities, 22(2), 649-664. 